ARTICLE

DOI: $10.1038 / s 41467-017-01020-6$

OPEN

\title{
Ets transcription factor GABP controls T cell homeostasis and immunity
}

Chong T. Luo (1) ${ }^{1,2}$, Hatice U. Osmanbeyoglu ${ }^{3}$, Mytrang H. Do ${ }^{1}$, Michael R. Bivona ${ }^{1}$, Ahmed Toure ${ }^{1}$, Davina Kang ${ }^{1}$, Yuchen $\mathrm{Xie}^{2}$, Christina S. Leslie ${ }^{3}$ \& Ming O. Li ${ }^{1}$

Peripheral T cells are maintained in the absence of vigorous stimuli, and respond to antigenic stimulation by initiating cell cycle progression and functional differentiation. Here we show that depletion of the Ets family transcription factor GA-binding protein (GABP) in T cells impairs T-cell homeostasis. In addition, GABP is critically required for antigen-stimulated T-cell responses in vitro and in vivo. Transcriptome and genome-wide GABP-binding site analyses identify GABP direct targets encoding proteins involved in cellular redox balance and DNA replication, including the $\mathrm{Mcm}$ replicative helicases. These findings show that GABP has a nonredundant role in the control of T-cell homeostasis and immunity.

\footnotetext{
${ }^{1}$ Immunology Program, Memorial Sloan Kettering Cancer Center, New York, NY 10065, USA. ${ }^{2}$ Louis V. Gerstner Jr. Graduate School of Biomedical Sciences, Memorial Sloan Kettering Cancer Center, New York, NY 10065, USA. ${ }^{3}$ Computational Biology Program, Memorial Sloan Kettering Cancer Center, New York, NY 10065, USA. Correspondence and requests for materials should be addressed to M.O.L. (email: lim@mskcc.org)
} 
T he peripheral naive $\mathrm{T}$-cell population is maintained in number, diversity, and functional competence under steady-state conditions ${ }^{1}$. This homeostasis relies on signals from T-cell receptor (TCR) self-peptide major histocompatibility complex interaction and the common gamma chain cytokine interleukin $7(\mathrm{IL}-7)^{2}$. Upon microbial challenge, pathogenspecific $\mathrm{T}$ cells grow in size, followed by robust proliferation and differentiation into effector $\mathrm{T}$ cells ${ }^{3}$. Disruption of naive $\mathrm{T}$-cell homeostasis and effector T-cell responses results in debilitating and lethal diseases associated with immunodeficiency ${ }^{4}$.

A multitude of transcription factors have been described as important regulators of T-cell responses. For example, the forkhead box O (Foxo) family of transcription factors are essential for naive $\mathrm{T}$-cell survival and trafficking, in part through the regulation of IL-7 receptor $\alpha$-chain (IL-7R $\alpha$ ), L-selectin (CD62L) and the chemokine receptor CCR $7^{5}$. In addition, the E twenty-six (Ets) family of transcriptional factors, characterized by a conserved DNA-binding domain that recognizes nucleotide sequences with a GGAA/T core motif, have been implicated in T-cell regulation $^{6}$. T cells deficient in Ets1 are more susceptible to cell death $^{7,8}$. By contrast, depletion of Elf4 results in enhanced homeostatic and antigen-drive proliferation of $\mathrm{CD}^{+} \mathrm{T}$ cells ${ }^{9}$, suggesting that Ets proteins can function as both positive and negative modulators of peripheral T-cell responses.

Compared with other Ets family transcription factors, GA-binding protein (GABP) is a unique member as it functions as an obligate multimeric complex ${ }^{10}$. GABP is composed of GABP $\alpha$, which binds to DNA through its Ets domain but lacks transactivation capability, and GABP $\beta$ that is recruited by GABP $\alpha$ and contains the transcription activation domain ${ }^{11,12}$. GABP $\alpha$ has a single transcript isoform that is widely expressed across tissue types, whereas GABP $\beta$ has multiple isoforms and some can dimerize, allowing for the formation of a $\mathrm{GABP} \alpha_{2} / \beta_{2}$ heterotetramer complex ${ }^{13,14}$. Targets of GABP include housekeeping genes, such as those involved in ribosomal and mitochondrial biogenesis $^{10,15,16}$, which might account for the embryonic lethal phenotype of GABP $\alpha$-deficient mice ${ }^{17,18}$. GABP also regulates tissue-restricted targets such as acetylcholine receptors in neuro- muscular synapse and integrin- $\beta 2$ in myeloid cells ${ }^{19,20}$. Moreover, GABP has been shown to facilitate the progression of multiple cancers, including chronic myeloid leukemia, liver cancer, and glioblastomas ${ }^{21-24}$.

Studies of GABP in T cells have mainly focused on its role in the control of $I l 7 \mathrm{ra}$ transcription ${ }^{18}$. Analysis of embryonic thymocytes from mice harboring constitutive depletion of the Gabpa gene revealed a complete abolishment of IL-7R $\alpha$ expression $^{18}$. A later report using $\mathrm{Lck}$-Cre to trigger conditional knockout of Gabpa gene from $\mathrm{CD}^{-} \mathrm{CD}^{-}$double-negative (DN) 1-DN2 thymocytes showed that T-cell development was arrested at the DN3 stage ${ }^{25}$. However, IL-7R $\alpha$ expression was not defective in DN3 thymocytes, and it was only partially reduced in DN4 cells $^{25}$. Furthermore, ectopic expression of IL-7R $\alpha$ failed to alleviate the $\mathrm{DN} 3$ block caused by GABP $\alpha$ ablation ${ }^{25}$, suggesting that GABP $\alpha$ regulation of early T-cell development is independent of IL-7R $\alpha$. Nevertheless, it is unclear whether GABP $\alpha$ regulates IL$7 \mathrm{R} \alpha$ expression in mature $\mathrm{T}$ cells, and whether GABP $\alpha$ has additional functions in the control of T-cell homeostasis and effector T-cell responses.

In this report, we utilize a mouse model that ablates GABP $\alpha$ from $\mathrm{CD}^{+} \mathrm{CD}{ }^{+}$double-positive (DP) thymocytes. We find that although $\mathrm{T}$-cell development is largely unperturbed, loss of GABP $\alpha$ triggers a diminishment of peripheral T-cell populations. In vitro culture experiments show that $\mathrm{GABP} \alpha$ is crucial for T-cell activation, proliferation, and survival upon antigen challenge. Mechanistic studies identify GABP target genes involved in the control of cellular redox balance, DNA replication, and cell cycle progression. Consequently, depletion of GABP $\alpha$ impairs $\mathrm{T}$-cell homeostatic survival, proliferation, and antigen-induced responses in vivo. Collectively, our findings identify GABP as a central regulator of $\mathrm{T}$-cell homeostasis and T-cell immunity.

\section{Results}

T-cell development is unperturbed in $C D 4^{C r e} G a b p a f / f$ mice. $\mathrm{GABP} \alpha$ deficiency in T-cell progenitors results in compromised T-cell development ${ }^{18,25}$. To study the function of GABP $\alpha$ beyond a

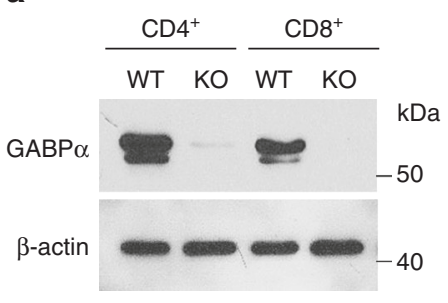

d

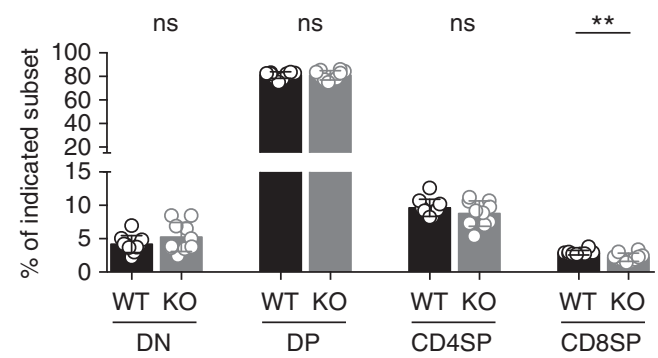

b

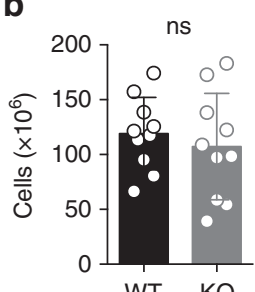

$\star \star$
C

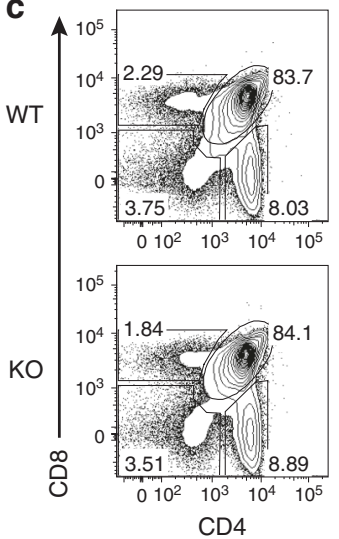

Fig. 1 Thymocyte development in T-cell-specific GABP $\alpha$-deficient mice. a Immunoblotting analysis of GABP $\alpha$ in purified $C D 4^{+}$and $C D 8^{+} T$ cells from the spleens and lymph nodes (LNs) of Gabpa ${ }^{f / f}$ (wild-type, WT) and $C D 4^{C r e} G_{a b p a}^{f / f}$ (KO) mice. $\beta$-actin was used as a loading control. Uncropped western blotting images were included in Supplementary Fig. 10. b Total numbers of thymocyte in WT and KO mice. c Flow cytometric analysis of CD4 and CD8 expression on thymocytes of WT and KO mice. d Percentages of $\mathrm{CD} 4^{-} \mathrm{CD} 8^{-}$(double-negative, DN), CD $4^{+} \mathrm{CD} 8^{+}$(double-positive, DP), $\mathrm{CD} 4^{+}$or $\mathrm{CD} 8^{+}$ single-positive (SP) subsets. Mice of 5-8-week old were used. Data represent 10 mice per genotype analyzed in at least three independent experiments (mean \pm SEM; unpaired $t$-test) 
the early stages of T-cell differentiation, we crossed mice carrying floxed Gabpa alleles (Gabpa $\left.a^{f / f}\right)^{26}$ with $C D 4^{C r e}$ transgenic mice in which the Cre recombinase is expressed in DP thymocytes. GABP $\alpha$ protein was barely detectable in $\mathrm{CD}^{+}{ }^{+}$or $\mathrm{CD}^{+} \mathrm{T}$ cells isolated from the spleen and lymph nodes (LNs) of $\mathrm{CD} 4^{\mathrm{Cre}-}$ Gabpa/f mice, revealing that Gabpa was efficiently deleted in both $\mathrm{CD}^{+}$and $\mathrm{CD}^{+} \mathrm{T}$ cells in these mice, hereafter designated as knockout (KO) mice (Fig. 1a). Thymic cellularity was comparable between 5- to 8-week-old KO mice and Gabpafff littermate controls, hereafter designated as wild-type (WT) mice (Fig. 1b). In addition, the proportions of DN, DP, and CD4 or CD8 singlepositive (SP) subsets were comparable between WT and KO mice, with the exception of $20 \%$ reduction of CD8SP cells in KO mice (Fig. 1c, d). These observations demonstrate that thymic selection is largely unaltered in $C D 4^{C r e} G a b p a^{f / f}$ mice.

GABP $\alpha$ deficiency impairs peripheral T-cell homeostasis. To investigate whether GABP $\alpha$ deficiency affects T-cell homeostasis, we enumerated total, $\mathrm{CD}^{+}$and $\mathrm{CD}^{+} \mathrm{T}$ cells in peripheral lymphoid organs. Compared to WT mice, GABP $\alpha$-deficient mice had about twofold reduction of splenic and LN TCR $\beta^{+}$cells (Fig. $2 \mathrm{a}-\mathrm{c}$ and Supplementary Fig. $1 \mathrm{a}-\mathrm{c}$ ). Among TCR $\beta^{+}$cells, $\mathrm{CD}^{+} \mathrm{T}$ cells were more severely affected, as the ratio of $\mathrm{CD} 4^{+}$to $\mathrm{CD}^{+} \mathrm{T}$ cells was higher in KO mice (Supplementary Fig. 1d, e). Further analysis of expression of the T-cell activation marker $\mathrm{CD} 44$ revealed that $\mathrm{KO}$ mice had reduced fractions of activated or memory phenotype $\mathrm{CD} 4^{+}$or $\mathrm{CD} 8^{+} \mathrm{T}$ cells (Fig. $2 \mathrm{~d}$ and Supplementary Fig. 1f). The number of CD $44^{\text {lo }}$ naive T cells and CD $44^{\text {hi }}$ activated memory $\mathrm{T}$ cells was reduced by 2 -3-fold and 5-7-fold, respectively, in KO mice (Fig. 2e and Supplementary Fig. 1g). Together, these findings reveal an essential role for GABP $\alpha$ in the maintenance of peripheral $\mathrm{T}$ cells.

Naive T-cell homeostasis is dependent on CD62L and IL-7R $\alpha$ to support T-cell trafficking, survival, and homeostatic proliferation, and their expression is under the control of the forkhead family transcription factor Foxo ${ }^{27,28}$. To test whether GABP $\alpha$ is required for naive $\mathrm{T}$-cell survival in vitro, we purified naive $\mathrm{CD} 4^{+}$

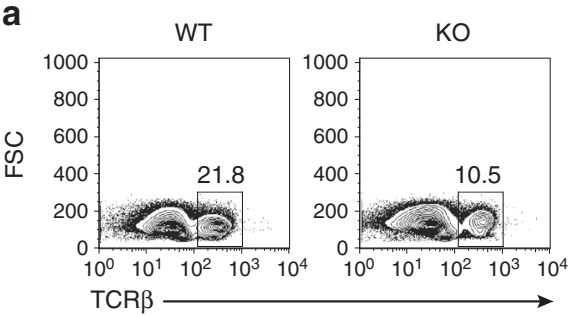

d

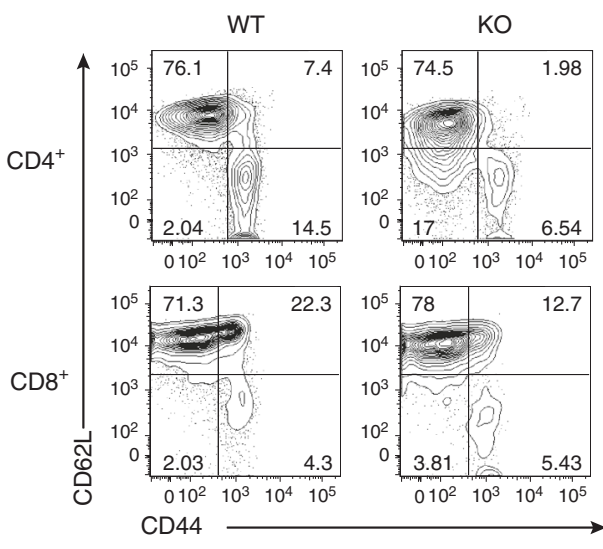

f

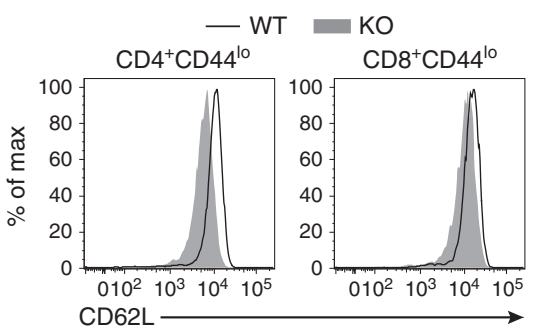

b
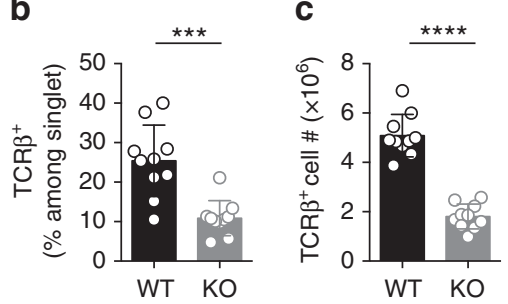

e

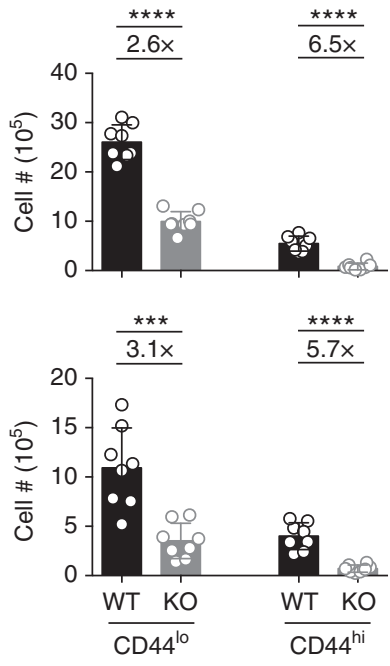

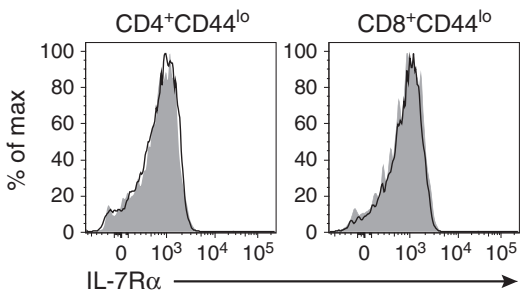

Fig. 2 Mice with T-cell-specific disruption of GABP $\alpha$ have fewer peripheral T cells. a Flow cytometric analysis of TCR $\beta$ expression on live singlet cells from spleen of $\mathrm{Gabpa}^{f / f}$ (wild-type, WT) and CD4 ${ }^{\mathrm{Cre}} \mathrm{Gabpa} / / f(\mathrm{KO})$ mice. b, c Fractions of TCR $\beta^{+}$cells among total live cells (b), and numbers of TCR $\beta^{+}$cells (c) in the spleens of WT and KO mice. $\mathbf{d}$ Flow cytometric analysis of CD44 and CD62L expression on CD4 ${ }^{+}$and CD8 ${ }^{+} \mathrm{T}$ cells from spleen of WT and KO mice. $\mathbf{e}$ Numbers of $\mathrm{CD} 44^{10}$ and $\mathrm{CD} 44^{\mathrm{hi}}$ subsets of $\mathrm{CD} 4^{+}$and $\mathrm{CD} 8^{+}$in the spleens of WT and KO mice. Fold changes comparing KO to WT are shown above the plots. $\mathbf{f}$ Expression of CD62L and IL-7R $\alpha$ in CD44 ${ }^{10}$ naive $C D 4^{+}$and $C D 8^{+} \mathrm{T}$ cells from spleens of WT and KO mice. Mice of 5-8-week old were used. Data represent 8-10 mice per genotype analyzed in at least three independent experiments (mean $\pm \mathrm{SEM}$; unpaired $t$-test). ns $=$ not significant. ${ }^{\star \star \star} P<0.001$, $\star \star \star \star P<0.0001$ 
and $\mathrm{CD} 8^{+} \mathrm{T}$ cells from WT and $\mathrm{KO}$ mice, and cultured them with IL-7 containing medium. Although both WT and KO cells retained naive and quiescent phenotype, loss of GABP resulted in compromised cell survival (Supplementary Fig. 2). Previous studies have implicated a role of GABP $\alpha$ in the transactivation of the $I l 7 r$ locus in $\mathrm{T}$ cells ${ }^{18,25}$, which might contribute to the GABP $\alpha$-dependent naive T-cell survival. Surprisingly, while CD44 ${ }^{\text {lo }}$ naive $\mathrm{T}$ cells from $\mathrm{GABP} \alpha$-deficient mice expressed modestly lower levels of CD62L than control cells from WT mice (Fig. 2d, f and Supplementary Fig. 1f, h), expression of IL-7R $\alpha$ was not different between WT and KO T cells (Fig. $2 \mathrm{f}$ and Supplementary Fig. 1h). Thus, the regulation of GABP $\alpha$ in T-cell homeostasis is independent of IL-7R $\alpha$-mediated mechanisms.

GABP $\alpha$ deficiency impairs antigen-induced T-cell responses. In addition to the naive T-cell defects, CD4 ${ }^{C r e} G a b p a^{f / f}$ mice possessed a more pronounced loss of activated memory $\mathrm{T}$ cells (Fig. 2e and Supplementary Fig. 1g). To determine whether GABP $\alpha$ is required for antigen-stimulated T-cell responses, we isolated naive $\mathrm{CD}^{+}$and $\mathrm{CD}^{+} \mathrm{T}$ cells from $\mathrm{WT}$ and $\mathrm{KO}$ mice, and stimulated them with $\mathrm{CD} 3$ and $\mathrm{CD} 28$ antibodies in the presence of IL-2. At 12-h post stimulation, GABP $\alpha$-replete and -deficient T cells upregulated CD69 and CD25 to a comparable level (Fig. 3a), suggesting that GABP $\alpha$ deficiency did not impair TCR signaling. However, in contrast to WT T cells, KO T cells failed to expand their cell size and further augment the expression of CD69 and CD25 at the 36-h time point (Fig. 3a). In line with the attenuated expression of activation markers, production of IL2 was abrogated in KO T cells as well (Fig. 3b). Furthermore, GABP $\alpha$-depleted $\mathrm{T}$ cells did not undergo cell division (Fig. $3 \mathrm{c}$ ), and they were more prone to cell death (Fig. 3d). To further test whether the GABP-mediated regulation is dependent on IL-2 receptor signaling, we stimulated WT and $\mathrm{KO} \mathrm{T}$ cells in the absence of exogenous IL-2, and similar defects in cell activation, proliferation, and survival in GABP-deficient $\mathrm{T}$ cells were observed (Supplementary Fig. 3). Collectively, these observations reveal a crucial function for GABP $\alpha$ in the control of T-cell activation, proliferation, and survival upon antigen challenge.

GABP $\alpha$ controls a distinct transcriptional program in $\mathrm{T}$ cells. To define the genetic programs by which GABP $\alpha$ controls T-cell responses, we performed transcriptome analysis of GABP $\alpha$ sufficient and -deficient cells. We purified naive $\mathrm{CD} 4^{+}$and $\mathrm{CD} 8^{+}$ $\mathrm{T}$ cells from WT and $\mathrm{KO}$ mice, and either extracted RNA from the sorted T cells ( 0 -h group), or stimulated T cells with anti-CD3 and anti-CD28 in the presence of IL- 2 for $18 \mathrm{~h}$ before RNA extraction (18-h group). As T-cell homeostasis and antigeninduced responses were affected in both $\mathrm{CD}^{+}$and $\mathrm{CD}^{+} \mathrm{T}$ cells, we focused on transcripts that had consistent changes between $\mathrm{CD}^{+}$and $\mathrm{CD}^{+} \mathrm{T}$ cells, and were differentially expressed between WT and KO T cells at 0 -h and/or 18-h time points. We uncovered 109 and 80 genes that were downregulated or upregulated, respectively, in $\mathrm{KO} \mathrm{T}$ cells by more than 1.5 -fold and with a false discovery rate $<0.05$ (Supplementary Data 1 ).

Gene ontology association analysis revealed that cellular processes including protein and nucleotide metabolism, protein transport and localization, cell cycle progression, cell death regulation, and cellular responses to stress were significantly overrepresented in the GABP $\alpha$-regulated genes (Supplementary Fig. 4 and Supplementary Data 2). Among the genes downregulated in KO T cells, $\sim 70 \%$ of them were differentially expressed at both 0 and 18-h time points. These genes encode proteins that are involved in basic cellular activities, such as microtubule organization and vesicle transportation (Ccz1, Nubp1, and Mcrs1), and mitochondrial biogenesis and function (Stoml2,
Romo1, Ndufaf1, Idh3b, Mrpl16, and Mrps35), which could explain the homeostatic defects manifested by both naive and activated T cells lacking GABP $\alpha$ (Supplementary Data 1 and Fig. 2e). Moreover, about $30 \%$ of the downregulated genes showed compromised expression in KO T cells only at the $18-\mathrm{h}$ time point (Supplementary Data 1). Many of these genes, including Tyms, Shmt1, Pola2, Lig1, Mcm3, and Mcm5, are important for folate-dependent de novo thymidylate biosynthesis and DNA replication. They were induced in WT cells in response to TCR stimulation, but the induction was abolished in the absence of GABP $\alpha$ (Supplementary Data 1). This additional group of activation-associated genes might be responsible for the exacerbated phenotype exhibited by GABP $\alpha$-deficient activated $\mathrm{T}$ cells compared with the naive counterparts (Fig. $2 \mathrm{~d}$, e). On the other hand, the genes that were upregulated in GABP-null cells are mainly involved in ER stress responses and the induction of apoptosis and senescence (Gadd45g, Ddit3, Phlda3, Pdia5, Blcap, and Phlda3), which may explain the survival defects of GABP $\alpha$ deficient T cells (Supplementary Data 1, Supplementary Fig. 3d, and Supplementary Fig. 2).

We wished to define the direct GABP $\alpha$-dependent transcriptional program in $\mathrm{T}$ cells. To this end, we performed chromatin immunoprecipitation coupled to high-throughput sequencing (ChIP-seq) experiments. Using a cutoff of false discovery rate of 0.01 , we uncovered 6782 genomic loci that were enriched in GABP $\alpha$ antibody pulldown compared with the chromatin input (Supplementary Data 3). We found that the GABP $\alpha$-binding sites were mostly enriched in gene promoter regions (Fig. 4a). De novo motif prediction from the peaks also revealed a conserved GABP $\alpha$ recognition site containing the GGAA core (Fig. 4b). In addition, we could identify previously characterized binding sites of GABP $\alpha$ target genes ${ }^{29}$, including the sites in the proximal promoter regions of Gabpa and Cox5b (Supplementary Fig. 6a). Nonetheless, $I l 7 r$ did not appear to be a GABP $\alpha$ target gene, as WT and KO cells contained comparable amounts of $I l 7 r$ mRNA, and no GABP $\alpha$-binding peak was found in the $I l 7 r$ gene locus (Supplementary Fig. 5b). These observations are consistent with the ex vivo analysis of IL-7R $\alpha$ (Fig. 2f and Supplementary Fig. 1h), further supporting IL-7R $\alpha$-independent mechanisms of $\mathrm{T}$-cell regulation by GABP $\alpha$.

By cross-referencing the transcriptome and the ChIP-seq data sets, we could identify 95 putative direct target genes of GABP $\alpha$, among which 70 and 25 were activated or repressed by GABP $\alpha$, respectively (Fig. 4c and Supplementary Data 4). Further gene ontology analysis revealed that the GABP $\alpha$ direct target genes were strongly associated with DNA replication, DNA repair, centrosome and cell cycle regulation, RNA processing, protein and sugar metabolism, signal transduction, and transcription (Fig. 4c, Supplementary Fig. 6, and Supplementary Data 5). Among the putative $\mathrm{GABP} \alpha$ direct targets are those encoding mitochondrial ribosomal proteins (Mrpl16 and Mrps35), mitochondrial membrane proteins (Stoml2 and Tmem126a), enzymes involved in mitochondrial protein synthesis and quality control (Mtx2, Oma1, and Mtif2), as well as essential components of electron transport chain and oxidative phosphorylation (Idh3b, Ndufaf1, and Dlst) (Fig. 4c). In line with these observations, GABP $\alpha$-deficient $\mathrm{T}$ cells possessed heightened levels of both cellular and mitochondrial reactive oxygen species (ROS) (Supplementary Fig. 7). These findings indicate a critical role for $\mathrm{GABP} \alpha$ in the control of cellular metabolism and redox balance, the deficiency of which may affect T-cell homeostasis.

GABP $\alpha$ promotes $\mathrm{Mcm}$ expression and DNA replication in T cells. Considering that several GABP $\alpha$ target genes were involved in cell cycle regulation and GABP $\alpha$-deficient $\mathrm{T}$ cells 
a

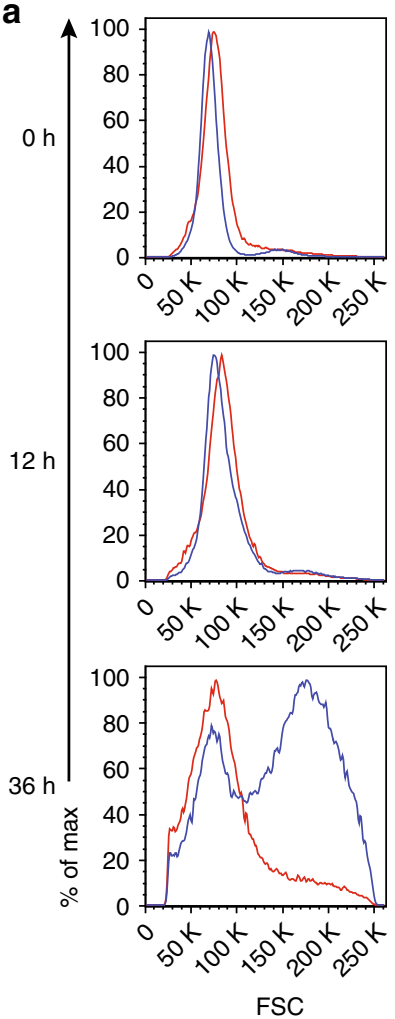

b

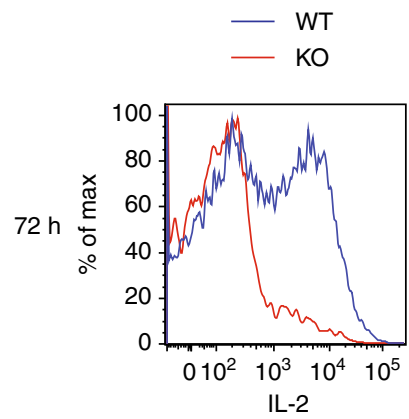

C

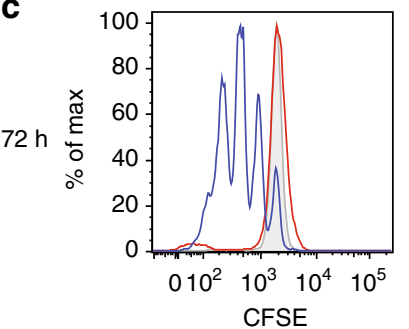

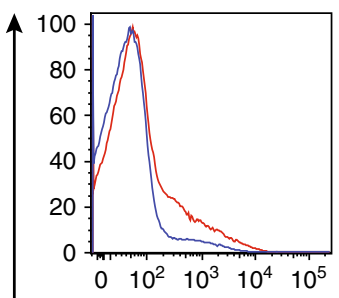
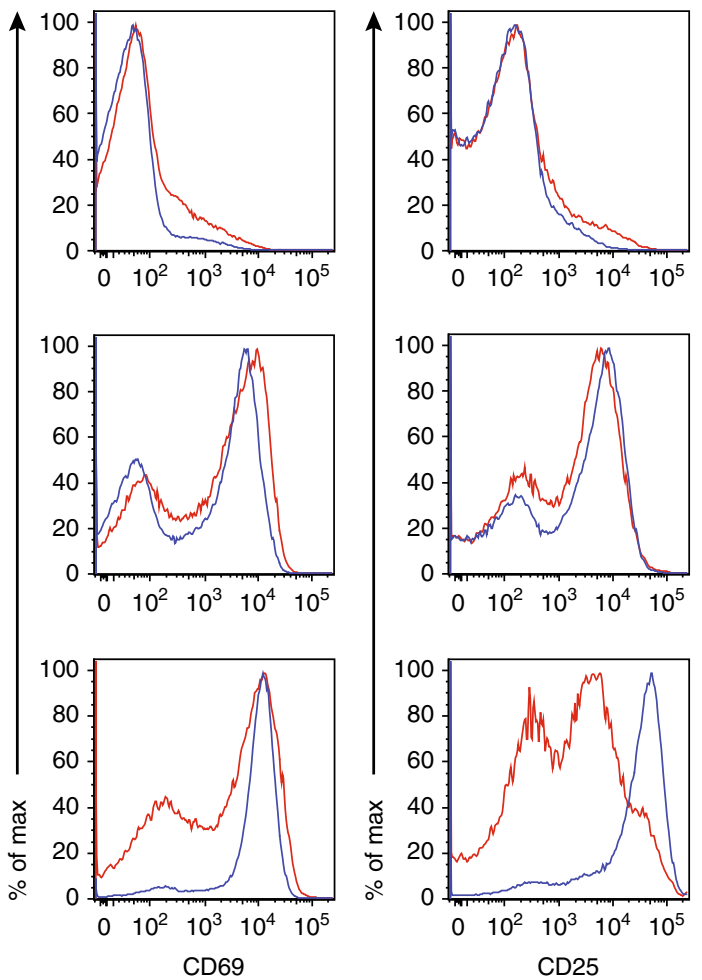

d
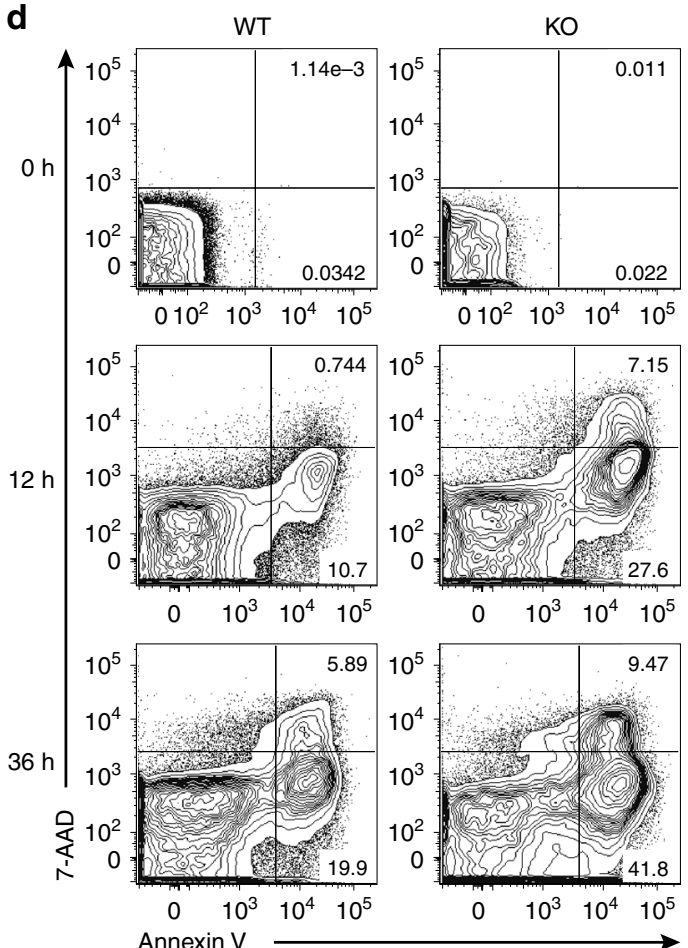

Fig. $3 \mathrm{GABP} \alpha$ is required for T-cell responses to antigen stimulation in vitro. Naive (CD62 $\left.\mathrm{L}^{\text {hi }} \mathrm{CD} 44^{\mathrm{lo}}\right) \mathrm{CD}^{+}$or $^{\mathrm{CD}} 8^{+} \mathrm{T}$ cells from Gabpat/f $(\mathrm{WT})$ and $\mathrm{CD}^{4}{ }^{\mathrm{Cr}} \mathrm{Gabpa}{ }^{f / f}(\mathrm{KO})$ mice were purified by flow cytometric sorting, and were subjected to anti-CD3 and anti-CD28 stimulation in the presence of IL-2. Representative plots from CD8 ${ }^{+} \mathrm{T}$-cell culture were shown. a Analysis of cell size (FSC) and activation markers, CD69 and CD25, at 0, 12, and 36 h post stimulation. b Seventy-two hour after cell culture, WT and KO cells were restimulated with PMA and ionomycin for $4 \mathrm{~h}$ and analyzed for the expression of IL-2 by intracellular cytokine staining. c WT and KO cells were labeled with the cytosolic dye CFSE, and cell division was assessed by the dilution of CFSE. Gray shaded line shows CFSE level of undivided cells. $\mathbf{d}$ Cell death was assessed with Annexin V and 7-AAD staining. Data represent at least three independent experiments 
a

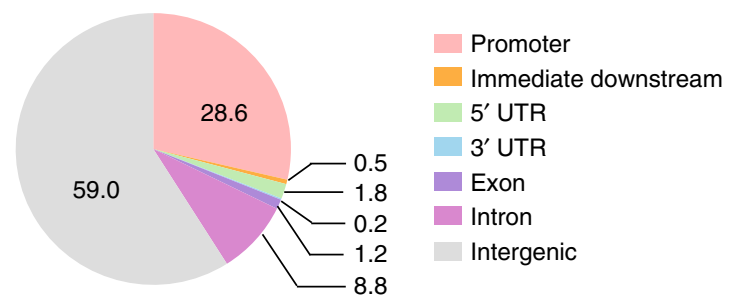

C
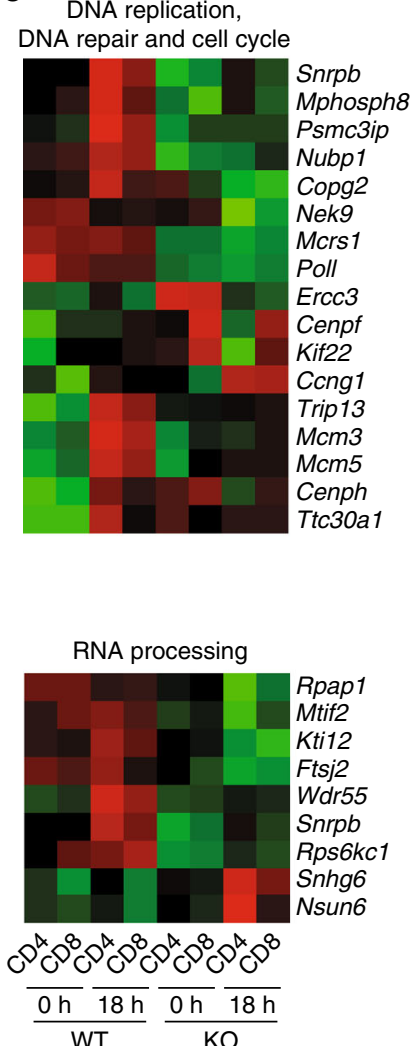

b

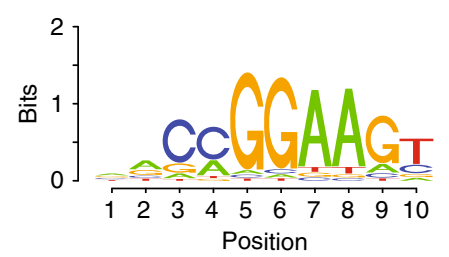

Cellular metabolism

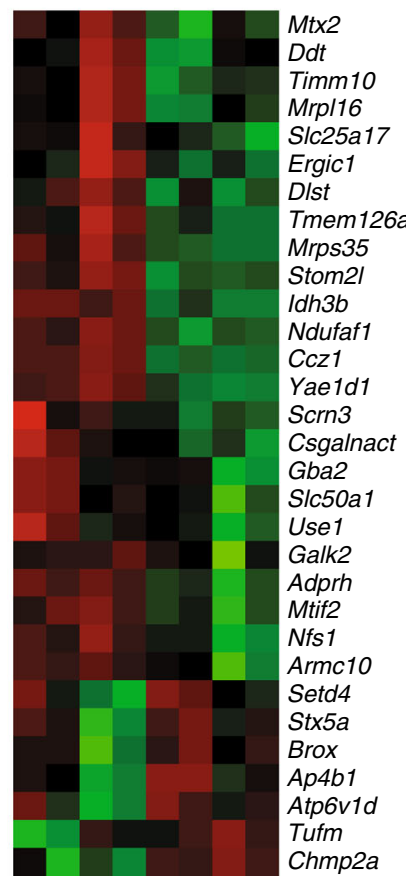

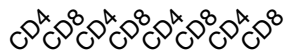

$\frac{0 \mathrm{~h}}{\mathrm{WT}} \frac{\overline{\mathrm{hh}} \overline{18 \mathrm{~h}}}{\mathrm{KO}}$
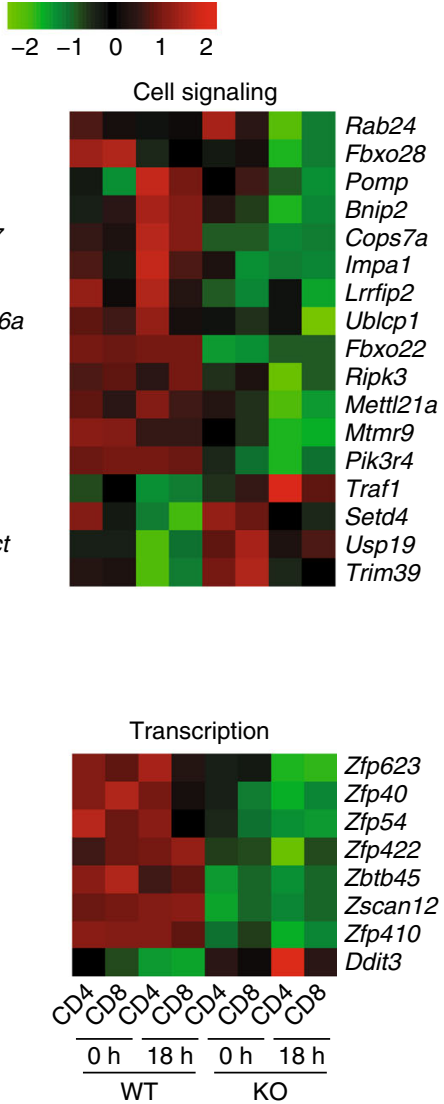

Fig. $4 \mathrm{GABP} \alpha$-dependent transcriptional program in T cells. a Pie chart of distribution of GABP $\alpha$-binding peaks discovered from ChIP sequencing. $\mathbf{b}$ The consensus sequence motif identified in the GABP $\alpha$-binding sites by the HOMER program. c Heat map of GABP $\alpha$ direct target genes in WT and GABP $\alpha$ deficient $C D 4^{+}$and $C D 8^{+} T$ cells at two different time points: 0-h, sorted (CD62 $\mathrm{L}^{\text {hi }} \mathrm{CD} 44^{\mathrm{lo}}$ ) naive $\mathrm{T}$ cells; 18 -h, sorted naive $T$ cells were subjected to antiCD3 and anti-CD28 stimulation in the presence of IL-2 for $18 \mathrm{~h}$. GABP $\alpha$ direct target genes were defined as: (1) differentially expressed between WT and GABP $\alpha$ knockout T cells at 0- or 18-h time point or both; (2) expression changes were consistent between CD4 ${ }^{+}$and $\mathrm{CD} 8^{+} \mathrm{T}$ cells; (3) GABP $\alpha$ was recruited to the gene locus in the ChIP-seq experiment. The genes were divided into five groups on the basis of gene ontology

failed to proliferate (Figs. $4 \mathrm{c}$ and $3 \mathrm{c}$ ), we wished to determine the exact stage of GABP $\alpha$-dependent cell cycle progression in T cells. To this end, we stimulated WT and KO T cells with CD3 and CD28 antibodies, and pulse-labeled T cells with EdU, a nucleoside analog of thymidine, which can be incorporated into the replicating DNA. Strikingly, while $\sim 20 \%$ WT cells incorporated EdU, less than 1\% GABP $\alpha$-deficient T cells did so (Fig. 5a). These observations demonstrate that GABP $\alpha$ promotes $\mathrm{S}$ phase transition in T cells.

Among the GABP $\alpha$ direct target genes, $M c m 3$ and $M c m 5$ have been implicated in the regulation of $S$ phase entry (Fig. 4c). The minichromosome maintenance $(\mathrm{Mcm})$ proteins are a family of highly conserved proteins that form a hexameric complex (Mcm2-7), which functions as a replicative helicase crucial for the initiation and elongation of DNA replication in eukaryotes ${ }^{30}$. TCR and CD28 stimulation of WT T cells induced the expression of $\mathrm{Mcm} 3$ and $\mathrm{Mcm} 5$, but this induction was diminished in
GABP-deficient $T$ cells (Fig. 4c). In addition, GABP $\alpha$ was recruited to the promoters of $M c m 3$ and $M c m 5$ (Fig. 5b), with evolutionarily conserved GABP-binding elements identified within these regions (Fig. 5c). Notably, the proximal promoter region of $\mathrm{Mcm} 3$ contained two GABP motifs that were 10-bp apart (Fig. 5c), which aligned well with the 10.5-bp periodicity of double-helical B-DNA and might act synergistically to recruit a GABP $\alpha_{2} \beta_{2}$ tetrameric complex ${ }^{14}$. Indeed, ChIP-qPCR experiments validated the binding of $\mathrm{GABP} \alpha$ to $\mathrm{Mcm} 3$ and $\mathrm{Mcm} 5$ promoters in both $\mathrm{CD}^{+}$and $\mathrm{CD}^{+} \mathrm{T}$ cells (Fig. $5 \mathrm{~d}$ ). We further tested the functional relevance of $\mathrm{Mcm} 3$ in the GABP $\alpha$-dependent cell cycle regulation via small hairpin RNA (shRNA) knockdown experiments (Supplementary Fig. 8). Knocking down $\mathrm{Mcm} 3$ in WT $\mathrm{T}$ cells resulted in reduced incorporation of EdU in response to anti-CD3 and anti-CD28 stimulation, which partially phenocopied the loss of GABP $\alpha$ (Supplementary Fig. 8). 
a

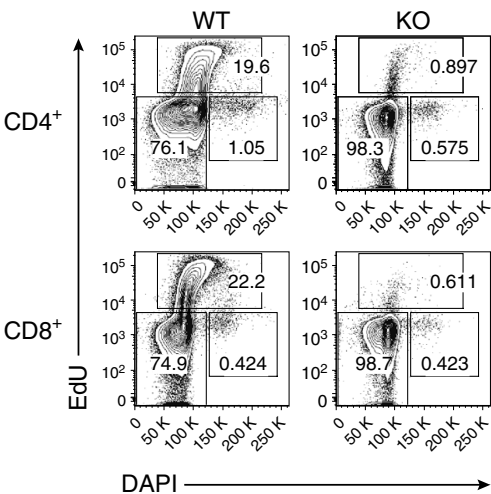

C

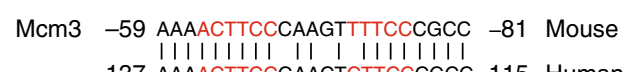

137 AAAACTTCCGAACTCTTCCCGCC 115 Human

Mcm5 -120 AGACCGGAAAGAG -108 Mouse II IIIIII III

-150 AGCCCGGAAGGA -138 Human

e

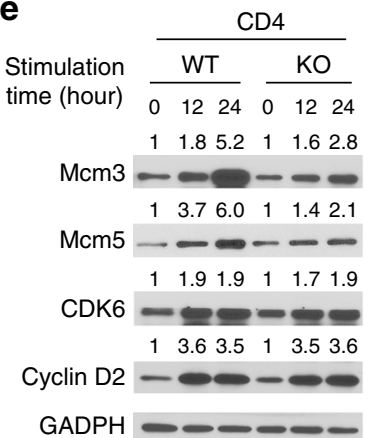

b

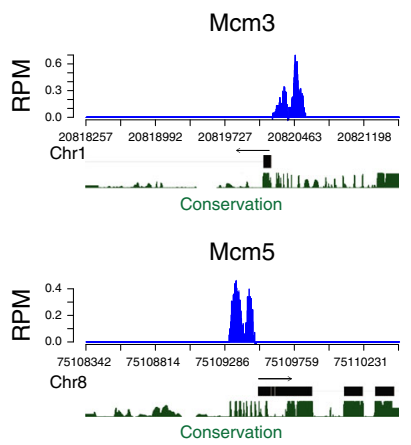

d

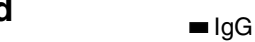

$-\mathrm{GABP} \alpha \mathrm{Ab}$
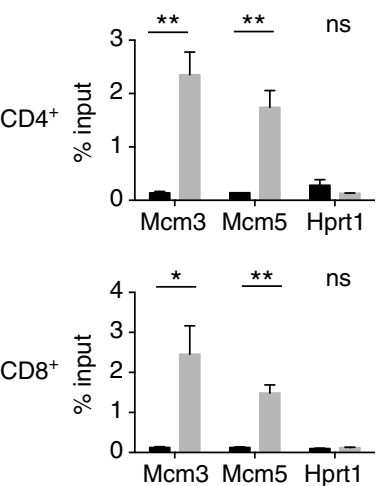

Fig. $5 \mathrm{GABP} \alpha$ regulates DNA replication and cell cycle progression. a Naive (CD62 $\left.\mathrm{L}^{\text {hi }} \mathrm{CD} 44^{\mathrm{lo}}\right) \mathrm{CD}^{+}$or $\mathrm{CD} 8^{+} \mathrm{T}$ cells from Gabpa ${ }^{f / f}(\mathrm{WT})$ and $\mathrm{CD}^{\mathrm{Cre}} \mathrm{Gabpa}{ }^{f / f}(\mathrm{KO})$ mice were purified by flow cytometric sorting, and were subjected to anti-CD3 and anti-CD28 stimulation in the presence of IL-2. After $22 \mathrm{~h}$, cells were pulsed with EdU for $2 \mathrm{~h}$. Flow cytometric analysis of DAPI and EdU was shown. $\mathbf{b}$ GABP $\alpha$-bound regions in the $M c m 3$ and $M c m 5$ gene loci. Gene structure, chromosomal location, and sequence homology were shown below the binding peaks. The $Y$-axis represent read per million (RPM). c Alignment of the conserved GABP $\alpha$-binding sites in mouse and human $\mathrm{Mcm} 3$ and $\mathrm{Mcm} 5$ proximal promoter regions. The consensus GABP $\alpha$-binding sequences were marked in red, and nucleotides were numbered relative to the transcription start site. d ChIP-qPCR validation of GABP $\alpha$ binding to the promoter regions of $\mathrm{Mcm} 3$ and $\mathrm{Mcm} 5$ genes in $\mathrm{WT} C D 4^{+} \mathrm{T}$ cells and $\mathrm{CD} 8^{+} \mathrm{T}$ cells. IgG was used as a control for the GABP $\alpha$ antibody. Hprt locus was used as a negative control. Bars are mean \pm SEM with unpaired $t$-test, ns $=$ not significant, ${ }^{\star} P<0.05,{ }^{\star \star} P<0.01$. e Naive CD4 ${ }^{+}$or CD $8^{+} \mathrm{T}$ cells from WT and KO mice were purified by flow cytometric sorting, and were stimulated with CD3 and CD28 antibodies in the presence of IL-2 for 0,12 , or $24 \mathrm{~h}$.

Immunoblotting analysis of Mcm3, Mcm5, CDK6, and Cyclin D2 was shown. GADPH was used as a loading control. The relative amounts of proteins were normalized to the 0 -h time point of each individual group. Uncropped western blotting images were included in Supplementary Fig. 10

In addition to the Mcm complex, another major component of cell cycle regulation is the ordered expression of cyclins and cyclin-dependent kinases $(\mathrm{CDKs})^{31}$. D-type cyclins and their catalytic partners, CDK4 and CDK6, are the first integrators of extracellular stimuli ${ }^{32}$. Following their induction in early G1 phase, cyclin D-CDK4/6 complexes phosphorylate key substrates, including $\mathrm{Rb}$, leading to the release of $\mathrm{E} 2 \mathrm{~F}$ transcription factors and transition into $S$ phase ${ }^{32}$. Intriguingly, while enhanced expression of $\mathrm{Mcm} 3$ and $\mathrm{Mcm} 5$ proteins was observed in WT cells following T-cell activation, expression of these proteins was greatly attenuated in GABP $\alpha$-null $\mathrm{T}$ cells (Fig. 5e). In contrast, the induction of cyclin D2 and CDK6 was not affected by the loss of GABP $\alpha$ (Fig. 5e), demonstrating that GABP $\alpha$ controls the cell cycle entry of $\mathrm{T}$ cells by specifically modulating the $\mathrm{Mcm}$-dependent pathway.

Cell-intrinsic role of GABP $\alpha$ in T-cell homeostatic proliferation. Having established a critical role of GABP $\alpha$ in T-cell cycle progression in vitro, we wished to investigate whether GABP $\alpha$ was required for T-cell homeostatic proliferation in vivo. To this end, we purified naive $\mathrm{CD} 4^{+}$and $\mathrm{CD} 8^{+} \mathrm{T}$ cells from congenically marked WT and KO mice, mixed them at 1:1 ratio, and labeled them by CFSE staining. We transferred these cells intravenously into Rag1-deficient or the sublethally irradiated C57/BL6 recipients (Fig. 6a), and assessed cell proliferation 7 days post transfer. In both Rag1-deficient and the irradiated C57/BL6 recipients, KO T cells exhibited reduced proliferation, and were out-competed by their WT counterparts (Fig. 6b). These findings indicate that GABP $\alpha$ deficiency impairs T-cell homeostatic proliferation in vivo.

GABP $\alpha$ is required for antigen-induced T-cell responses in vivo. To determine the function of GABP $\alpha$ in antigen-induced T-cell responses in vivo, we used a Listeria monocytogenes infection model. We used the L. monocytogenes strain that expresses ovalbumin (OVA) as a model antigen (LM-OVA). 
a
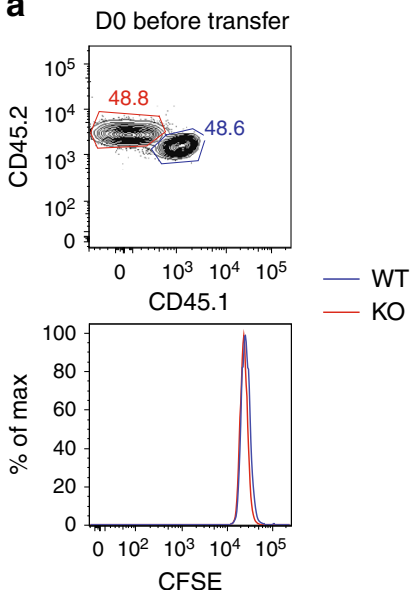

b

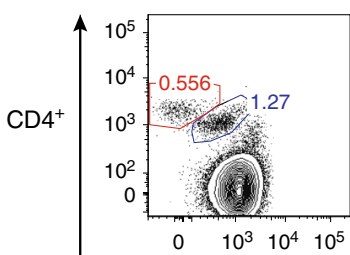

D7 post transfer

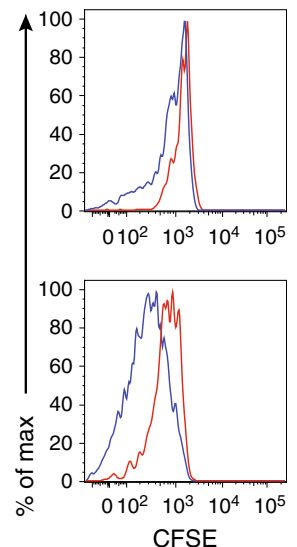

Fig. 6 A cell-intrinsic role of GABP $\alpha$ in control of T-cell homeostatic proliferation in vivo. CD4 ${ }^{+}$or $C D 8^{+} \mathrm{T}$ cells from WT (CD45.1/CD45.2) and KO (CD45.2/CD45.2) mice were mixed at a 1:1 ratio and transferred into $\mathrm{Rag}^{-/-}$or sublethally irradiated C57/B6 recipients (CD45.1/CD45.1). a The WT and $\mathrm{KO} \mathrm{CD8}{ }^{+} \mathrm{T}$-cell populations before transfer. The staining of the cytosolic dye CFSE was comparable between WT and KO cells. b Representative flow cytometric plots of transferred WT and KO cells in sublethally irradiated C57/B6 recipients at day 7 post transfer. Data represent at least three independent experiments

Clearance of the bacteria is mediated by $\mathrm{T}$ cells, among which $\mathrm{CD}^{+} \mathrm{T}$ cells provide the most substantial contribution to the protective immunity ${ }^{33}$. We crossed Gabpa $a^{f / f}$ mice to the OT-1 transgenic background to generate OVA-specific $\mathrm{CD}^{+} \mathrm{T}$ cells (OT-1 cells), and subsequently bred the Gabpa/f OT-1 mice with mice harboring the $C D 8^{\text {Cre }}$ transgene. GABP $\alpha$-replete and -depleted OT-1 cells were purified from cogenically marked mice, mixed at 1:1 ratio and stained with CFSE dye (Fig. 7a). T cells were transferred to recipient mice expressing a different congenic marker, which were subsequently challenged with a sublethal dose of LM-OVA. OT-1 cell responses in the spleen and liver, two major target organs of L. monocytogenes infection, were analyzed at days 3 and 7 post transfer. Compared with the WT OT-1 cells, a substantially lower proportion of KO OT-1 cells underwent cell division at day 3 (Fig. 7b, d). As a consequence, KO OT- 1 cells were markedly out-numbered by WT OT-1 cells at day 7 (Fig. 7c, e).

Given the striking defects GABP $\alpha$-null OT-1 cells exhibited upon LM-OVA infection, we next examined the endogenous Tcell responses in $C D 4^{C r e} \mathrm{Gabpaf/f}$ mice. Seven days after the LMOVA inoculation, a sizeable OVA-specific $\left(\mathrm{K}^{\mathrm{b}}\right.$-ova $\left.{ }^{+}\right) \mathrm{CD}^{+} \mathrm{T}$-cell population was found in WT mice (Fig. 7f, g). However, this antigen-specific subset was barely detectable in $C D 4^{C r e} G a b p a^{f / f}$ mice (Fig. 7f, g). The very limited pool of OVA-specific CD8 ${ }^{+}$ $\mathrm{T}$ cells in $C D 4^{\mathrm{Cre}} \mathrm{Gabpafff}$ mice was composed of comparable percentages of IL-7R $\alpha^{\text {hi }} \mathrm{KLRG}^{\mathrm{lo}}$ memory-precursor effector $\mathrm{T}$ cells and IL-7R $\alpha^{\mathrm{lo}} \mathrm{KLRG}{ }^{\text {hi }}$ short-lived effector $\mathrm{T}$ cells as their WT counterparts (Supplementary Fig. 9a, b). In addition, compared with GABP $\alpha$-replete cells, GABP $\alpha$-deficient $\mathrm{K}^{\mathrm{b}}$-ova ${ }^{+}$ cells expressed similar levels of the cytotoxic molecule, granyzme $\mathrm{B}$, as well as comparable or slightly reduced levels of the proinflammatory cytokine IFN- $\gamma$ (Supplementary Fig. 9c, d). Taken together, these observations demonstrate that $\mathrm{GABP} \alpha$ plays a crucial, cell-autonomous role in promoting antigen-specific T-cell responses.

\section{Discussion}

GABP has been shown to regulate early T-cell development ${ }^{18,25}$, yet its function in mature $\mathrm{T}$ cells has not been studied. Using a $\mathrm{CD} 4^{\mathrm{Cre}}$ conditional knockout system, we found that GABP $\alpha$ deficiency substantially impaired peripheral T-cell homeostasis while thymic development was largely unperturbed. Notably, the reduction of naive T cells was independent of IL-7R $\alpha$, which is a previously documented target of GABP $\alpha^{18}$. In addition, GABP $\alpha$ deficient $\mathrm{T}$ cells showed compromised activation, proliferation, and survival in response to antigenic stimulation in vitro. Mechanistically, by coupling transcriptome analysis with ChIPseq, we identified $\mathrm{GABP} \alpha$ as a vital regulator of cellular redox homeostasis, DNA replication, and cell cycle progression. Subsequent experiments further established the importance of GABP $\alpha$-dependent transcriptional program in the control of Tcell-mediated adaptive immunity in vivo, as depletion of GABP $\alpha$ undermined $\mathrm{T}$-cell homeostatic proliferation in lymphopenic environment as well as antigen-induced responses to microbial infection.

A surprising yet critical finding of this present study is that $\mathrm{GABP} \alpha$ is superfluous for $\mathrm{IL}-7 \mathrm{R} \alpha$ expression in mature $\mathrm{T}$ cells. Based on an earlier study, GABP $\alpha$ bound to a GGAA motif in the Il $7 r 5^{\prime}$ regulatory region, and knockdown of GABP $\alpha$ reduced IL$7 \mathrm{R} \alpha$ expression in vitro ${ }^{18}$. However, we found that neither the mRNA or protein level of $I l 7 r$ was perturbed by GABP $\alpha$ ablation in mature T cells. Nor did we observe any GABP $\alpha$-binding peak in the Il $7 r$ locus from our ChIP-seq. One plausible explanation for this discrepancy is the redundancy among the large Ets family transcription factors. It is possible that other Ets proteins that are highly expressed in peripheral T cells compete with GABP $\alpha$ in DNA binding, since they recognize and bind similar cognate DNA sequences $^{6}$. Indeed, several genome-wide ChIP experiments revealed co-occupancy of the same genomic regions by multiple Ets proteins ${ }^{34-36}$. An alternative explanation is that other transcription factors and cofactors are recruited to the $I l 7 r$ regulatory region in peripheral T cells, thus precluding the access of GABP $\alpha$. Consistent with this notion, Foxol has been shown to bind a conserved site in the $I l 7 r$ proximal promoter ${ }^{28}$, which overlaps with the proposed GABP $\alpha$-binding motif ${ }^{18}$. Moreover, the transcriptional repressor Gfi-1 has also been implicated in the regulation of $I l 7 r$ expression ${ }^{37}$. The functional interaction between $\mathrm{GABP} \alpha$ and these transcription factors awaits further investigation.

Our findings here demonstrate that $\mathrm{GABP} \alpha$ facilitates homeostatic proliferation of naive $\mathrm{T}$ cells as well as clonal expansion of antigen-specific $\mathrm{T}$ cells. On the molecular level, $\mathrm{GABP} \alpha$ regulates multiple genes involved in DNA replication and 
a

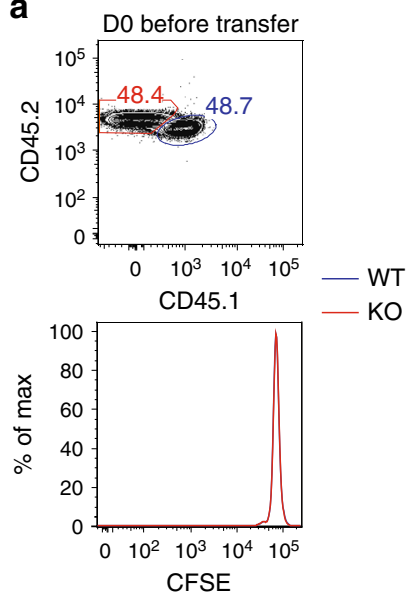

d

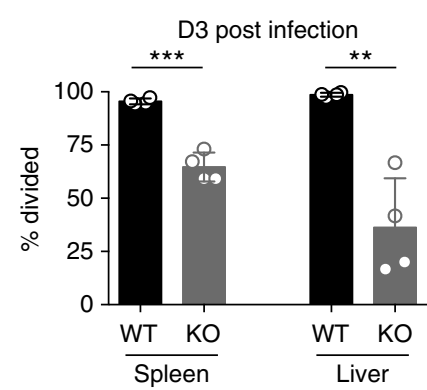

$\mathbf{f}$
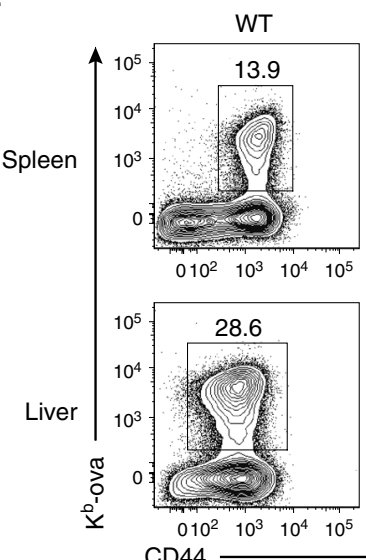

b
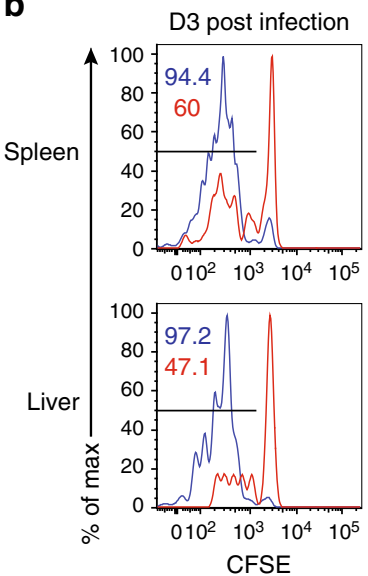

C
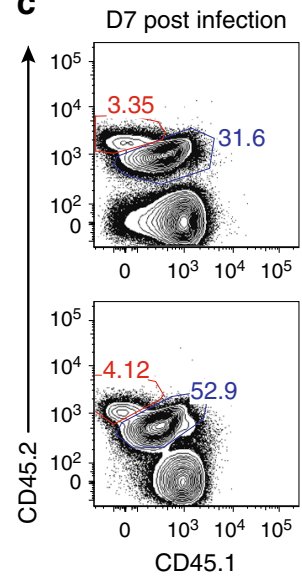

e

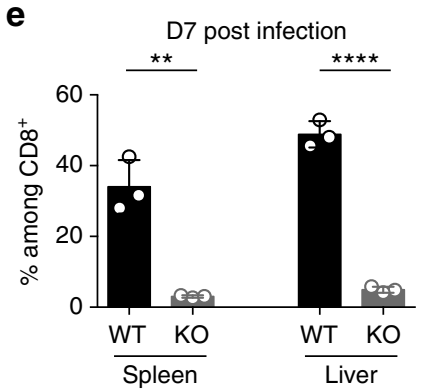

g

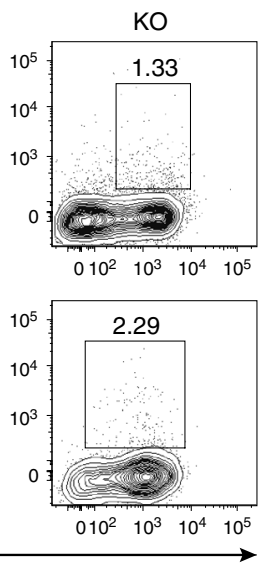

Fig. $7 \mathrm{GABP} \alpha$ controls $T$ cell responses to L. monocytogenes infection. a-e OT-1 cells from Gabpa $a^{f / f}$ OT-1 (WT, CD45.1/CD45.2) and CD8 $8^{\mathrm{Cre}}$ Gabpa ${ }^{f / f} \mathrm{OT}-1$ $(K O, C D 45.2 / C D 45.2)$ mice were mixed at a 1:1 ratio and transferred into WT recipients (CD45.1/CD45.1). The recipients were infected with LM-OVA a day after the cell transfer. a The WT and KO OT-1 T cells before transfer. b Dilution of CFSE at day 3 post infection. c Representative flow cytometric plots of transferred WT and KO cells at day 7 after inoculation. d Fractions of cells that have diluted CFSE at D3 p.i. e Enumeration of WT and KO cells at D7 p.i. 4 mice (D3 p.i.) or 3 mice (D7 p.i.) were included. f, g Gabpa f/f (WT) and CD4Cre Gabpat/f (KO) mice were infected with LM-OVA. At day 7 post infection, OVA-specific $C D 8^{+} T$-cell responses were analyzed by the staining of $\mathrm{K}^{\mathrm{b}}$-ova tetramer. $\mathbf{f}$ Representative flow cytometric blots of CD44 and $\mathrm{K}^{\mathrm{b}}$-ova staining in CD8 ${ }^{+} \mathrm{T}$ cells from spleen and liver. $\mathbf{g}$ Fractions of $\mathrm{K}^{\mathrm{b}}$-ova ${ }^{+} \mathrm{T}$ cells among the $\mathrm{CD} 8^{+}$population. Data represent three-five mice per genotype analyzed in at least three independent experiments. Bars are mean \pm SEM with an unpaired $t$-test, ns $=$ not significant, ${ }^{\star \star} P<0.01$,

${ }^{\star \star \star} P<0.001,{ }^{\star \star \star \star} P<0.0001$

cell cycle progression, among which include the $\mathrm{Mcm}$ genes. Proper assembly, loading, and activation of the $\mathrm{Mcm}$ 2-7 helicase complex are crucial for DNA replication ${ }^{30}$. Because yeast contains stable levels of $\mathrm{Mcm}$ mRNAs and proteins during cell cycle, the majority of studies have focused on the loading and subsequent activation of $\mathrm{Mcm}$ complexes rather than transcriptional regulation of $\mathrm{Mcm}$ genes ${ }^{30,38}$. Nevertheless, several studies revealed that mammalian cells show a dramatic upregulation of $\mathrm{Mcm}$ mRNAs in response to mitogenic cues, such as serum stimulation of resting fibroblasts and stimulation of human primary $\mathrm{T}$ cells with
CD3/CD28 antibodies ${ }^{39,40}$. Silencing $\mathrm{Mcm}$ genes in T cells causes premature chromatid separation and gross genomic instability ${ }^{39}$, implying that although poorly understood, the transcriptional mechanism of $\mathrm{Mcm}$ expression is, at least in part, central to the regulation of $\mathrm{Mcm}$ activities. To date, E2F has been the only transcription factor implicated in the $M c m$ transcription ${ }^{41,42}$. In this report, we identified $\mathrm{GABP} \alpha$ as another key transcription activator of the $\mathrm{Mcm}$ genes in $\mathrm{T}$ cells. Our future work will explore whether GABP $\alpha$ collaborates with the E2F transcription factors in this regulation and how it occurs. 
In fact, GABP $\alpha$-mediated cell cycle control has been implicated in previous studies. A report on mouse embryonic fibroblasts showed that GABP modulates the expression of Tyms, Skp2, and Pola1 through a cyclin D-CDK4/6-independent pathway ${ }^{16}$. In line with this report, we found that GABPo-deficient T cells contained reduced levels of Tyms, Skp2, and Pola1 mRNAs, while the expression of cyclin D2 or CDK6 was not affected. Additionally, we identified weak binding peaks of GABP $\alpha$ in the promoter regions of Tyms, Skp2, and Pola1, although their intensity was lower than our stringent cutoff. These findings indicate that GABP $\alpha$-mediated cell cycle regulation might be broadly applicable. Indeed, cell cycle blockade caused by GABP $\alpha$ depletion was observed in other cell types, including hematopoietic stem cells, vascular smooth muscle cells, and a human liver carcinoma cell line ${ }^{16,22,23,43}$

Besides the cell cycle arrest, GABP $\alpha$-deficient T cells are more prone to cell death. The survival defects can be partially attributed to the abortive cell division, yet additional GABP $\alpha$-mediated programs can contribute to this phenotype. We found that various cellular metabolic processes were deregulated in GABP $\alpha$ deficient $\mathrm{T}$ cells, which was associated with disrupted antioxidant defense and reduced cellular fitness. In line with our observations, knockdown or depletion of GABP $\alpha$ triggered augmented cell death in mouse hematopoietic stem cells and a human liver carcinoma cell line, despite that different mechanisms were proposed $^{23}$, 29. Initially identified as nuclear respiratory factor 2 , GABP has been shown to control both mitochondrial DNA genes and nuclear genes ${ }^{10,15}, 44$. Although we did not observe a loss of mitochondria mass (data not shown), numerous components of the tricarboxylic acid cycle and electron transport chain were expressed at low levels in GABP $\alpha$-deficient T cells. We will elucidate the impact of GABP $\alpha$ on different metabolic programs in mature $\mathrm{T}$ lymphocytes in our future studies.

In conclusion, in this report we have identified a critical role for GABP in naive T-cell homeostasis and antigen-stimulated effector responses. This was mediated in part by GABP control of cell cycle progression and cellular metabolism. Manipulation of the GABP pathway may provide novel therapeutic strategies for T-cell-mediated disorders, including infectious diseases and autoimmunity.

\section{Methods \\ Mice. All mice were on C57BL/6 background. The GABPa $a^{f / f}$ mouse strain was kindly provided by Dr Steve Burden (New York University) ${ }^{26}$. The CD4-Cre and OT-1 transgenic mice were described previously ${ }^{28,}{ }^{45} \cdot \mathrm{CD}^{-} \mathrm{Cre}^{46}$ and $\mathrm{CD} 45.1^{+}$ mice were purchased from Jackson Laboratory. In all experiments, littermate controls were used when possible. Both male and female mice were included. All mice were maintained under specific pathogen-free conditions, and all animal experimentation was approved by the Institutional Animal Care and Use Com- mittee of Memorial Sloan Kettering Cancer Center.}

Cell isolation. After whole-body perfusion with $50 \mathrm{ml}$ of heparinized PBS, lymphocytes were isolated as follows. Single-cell suspensions were prepared from spleens and peripheral (axillary, brachial, and inguinal) lymph nodes by tissue disruption with glass slides. To isolate cells from the liver, tissues were finely minced and digested with $1 \mathrm{mg} / \mathrm{ml}$ Collagenase $\mathrm{D}$ (Worthington) for $30 \mathrm{~min}$ at $37^{\circ} \mathrm{C}$. After the digestion, cells were filtered through $70 \mu \mathrm{M}$ cell strainer, layered in a 44 and 66\% Percoll gradient (Sigma), and centrifuged at $3000 \mathrm{rpm}$ for $30 \mathrm{~min}$ without brake. Cells at the interface were collected and analyzed by flow cytometry.

T-cell culture. Naive $\left(\mathrm{CD} 25^{-} \mathrm{CD} 62 \mathrm{~L}^{\text {hi }} \mathrm{CD} 44^{\text {lo }}\right) \mathrm{CD} 4^{+}$and $\mathrm{CD} 8^{+} \mathrm{T}$ cells were purified from spleen and lymph nodes of Gabpafff (WT) and $\mathrm{CD}^{4}{ }^{\mathrm{Cre}} \mathrm{Gabpat/f}$ (KO) mice by flow cytometry sorting (BD FACS Aria). Sorted T cells were cultured with plate-bound $\alpha$-CD3 (Clone 145-2C11, coated overnight, $5 \mu \mathrm{g} / \mathrm{ml}$ ), soluble $\alpha$-CD28 (Clone: $37.51,2 \mu \mathrm{g} / \mathrm{ml})$ and IL-2 $(100 \mathrm{U} / \mathrm{ml})$, or with IL-7 $(10 \mathrm{ng} / \mathrm{ml})$ for indicated time periods. For EdU incorporation experiments, the cells stimulated with were $\alpha-\mathrm{CD} 3 / 28$ and IL-2 for $22 \mathrm{~h}$ and EdU $(10 \mu \mathrm{M})$ was added into the culture for $2 \mathrm{~h}$.

shRNA knockdown. Short hairpin RNA targeting Mcm3 or scramble sequences were packed into a retroviral vector expressing GFP, and transfected into
HEK293T cells with calcium phosphate. Naive $\mathrm{CD}^{+} \mathrm{T}$ cells isolated from WT C57BL/6 mice were activated with plate-bound $\alpha$-CD3 (coated overnight, $5 \mu \mathrm{g} / \mathrm{ml}$ ), soluble $\alpha$-CD28 $(2 \mu \mathrm{g} / \mathrm{ml})$, and IL-2 $(100 \mathrm{U} / \mathrm{ml})$ for $18 \mathrm{~h}$ and were transfected with shRNA expressing retrovirus and sorted based on their GFP expression. Cells were rest for $18 \mathrm{~h}$ prior to EdU incorporation assessment. The shRNA sequence for $\mathrm{Mcm} 3$ is: GATTGCCTGTAATGTGAAGCAGATGAGTA.

Adoptive transfer of $\mathbf{T}$ cells. $\mathrm{CD} 4^{+}$or $\mathrm{CD}^{+} \mathrm{T}$ cells from Gabpa ${ }^{f / f}$ (WT, $\mathrm{CD} 45.1 / \mathrm{CD} 45.2)$ and $\mathrm{CD} 4^{\mathrm{Cre}} \mathrm{Gabpa} a^{\mathrm{flf}}$ (KO, CD45.2/CD45.2) mice were purified by flow cytometric sorting (BD Aria 2), mixed at a 1:1 ratio, stained with CFSE $(5 \mu \mathrm{M}$ final concentration at room temperature for $5 \mathrm{~min}$ ), and transferred into Ragdeficient or sublethally irradiated WT recipients (CD45.1/CD45.1) via intravenous injection. A total number of $2 \times 10^{6}$ cells were transferred into each recipient. Spleen and lymph nodes were analyzed 7 days after transfer.

For OT-1 transfer experiment, OT-1 cells from Gabpa $a^{f / f} O T-1$ (WT, $\mathrm{CD} 45.1 / \mathrm{CD} 45.2)$ and $\mathrm{CD} 8^{\mathrm{Cre}} \mathrm{Gabpa} a^{f / f} \mathrm{OT}-1$ (KO, CD45.2/CD45.2) mice were purified by flow cytometric sorting (BD Aria 2), mixed at a 1:1 ratio, stained with CFSE (5 $\mu \mathrm{M}$ final concentration), and intravenously transferred into WT recipients (CD45.1/CD45.1). A total number of $1.5 \times 10^{5}$ OT-1 cells were transferred $(7.5 \times$ $10^{4} /$ genotype).

Listeria monocytogenes infection. For the study of primary immune response, mice were intravenously infected with $5 \times 10^{3}$ colony-forming units ( $\mathrm{cfu}$ ) of Listeria monocytogenes expressing ovalbumin (LM-OVA), and spleens and livers were isolated for analysis 7 days after infection. For OT-1 transfer experiments, mice that had received OT-1 cells were intravenously infected with $1 \times 10^{5} \mathrm{cfu}$ of LM-OVA 1 day after the adoptive T-cell transfer. Spleens and livers of the infected mice were analyzed 3 and 7 days post infection.

Flow cytometry. Fluorochrome-conjugated antibodies against CD45.1 (clone 104) CD45.2 (A20), TCR- $\beta$ (H57-595), CD4 (RM4-5), CD8 (17A2), CD25 (PC61.5), CD44 (IM7), CD62L (MEL-14), CD69 (H1.2F3), IL-2 (JES605H4), IL-7R $\alpha$ (A7R34), IFN- $\gamma$ (XMG1.2), and KLRG-1 (2F1) were purchased from eBioscience. Anti-GzmB (GZ11) was purchased from Invitrogen. All antibodies were tested with their respective isotype controls. PE-conjugated $\mathrm{K}^{\mathrm{b}}$-ova tetramer was obtained from the Tetramer Core Facility at Memorial Sloan Kettering Cancer Center. Cell surface staining was performed by incubating cells with specific antibodies for 30 min on ice in the presence of $2.4 \mathrm{G} 2 \mathrm{mAb}$ to block Fc $\gamma \mathrm{R}$ binding. IL-2 staining was carried out using the intracellular cytokine staining kits from BD Biosciences. To determine cytokine expression, isolated cells were stimulated with $50 \mathrm{ng} / \mathrm{ml}$ phorbol 12-myristate 13-acetate (Sigma), $1 \mathrm{mM}$ ionomycin (Sigma), and GolgiStop (BD Biosciences) for $4 \mathrm{~h}$ prior to staining. For IFN- $\gamma$ expression of LM-OVAinfected mice, lymphocytes were stimulated with $10 \mathrm{nM}$ SIINFEKL peptide in the presence of GolgiStop (BD) for $5 \mathrm{~h}$ at $37^{\circ} \mathrm{C}$. Apoptotic cell death staining was performed with Annexin $\mathrm{V}$ staining kit (BD) according to the manufacturer's instructions. Cellular ROS and mitochondrial ROS levels were determined by $2^{\prime}, 7^{\prime}$-dichlorodihydrofluorescein diacetate (H2DCFDA) and MitoSOX red staining, respectively (ThermoFisher). Incorporation of EdU was measured using the Click-iT EdU flow cytometry assay kit (Invitrogen). For all stains, dead cells were excluded from analysis by means of Live/Dead Fixable Dye (Invitrogen), DAPI, or propidium iodide (PI) stain. All samples were acquired and analyzed with LSRII flow cytometer (Becton Dickson) and FlowJo software (TreeStar).

Gene-expression profiling. Naive $\left(\mathrm{CD} 25^{-} \mathrm{CD} 62 \mathrm{~L}^{\mathrm{hi}} \mathrm{CD} 44^{\mathrm{lo}}\right) \mathrm{CD} 4^{+}$and $\mathrm{CD} 8^{+}$ $\mathrm{T}$ cells were purified from spleen and lymph nodes of Gabpafff (WT) and $\mathrm{CD} 4^{\mathrm{Cre}} \mathrm{Gabpafff}(\mathrm{KO})$ mice by FACS sorting. Half of the sorted naive T cells was used for the 0 -h time point, whereas the other half of cells was subject to $\alpha$-CD3/28 and IL-2 stimulation for $18 \mathrm{~h}$. At indicated time points, cells were lysed using QIAZol reagent (Qiagen), followed by RNA extraction with the miRNeasy Mini Kit according to the manufacturer's instructions (Qiagen). Two rounds of RNA amplification, labeling, and hybridization to M430 2.0 chips (Affymetrix) were carried out at the Genomics Core of Memorial Sloan Kettering Cancer Center. Gene-expression profiling analyses were done with $\mathrm{R}$ statistical environment. Affymetrix CEL files of microarray experiments were processed using the "affy" package and differential expression was assessed using "limma" 47 package of the Bioconductor Suite (http://www.bioconductor.org/). A linear model was fitted to each gene, and empirical Bayes moderated $t$-statistics were used to assess differences in expression using limma package ${ }^{47}$. Empirical Bayes moderated- $t P$ values were computed relative to a fold-change cutoff of 1.5 -fold using WT samples. Genes were considered differentially expressed (GABP $\alpha$-dependent) if they had an FDR less than 0.05 .

ChIP-seq. CD $4^{+} \mathrm{T}$ cells of WT mice were purified by MACS beads (Miltenyi) and fixed for $10 \mathrm{~min}$ at room temperature with $10 \%$ formaldehyde. Glycine was added to a final concentration of $0.125 \mathrm{M}$ to quench the formaldehyde. Cells were pelleted, washed twice, and ice-cold PBS and lysed with hypotonic lysis buffer. Chromatin was sheared with Bioruptor sonicator (Diagenode) to $200-500$ base pairs (bp) in length. The prepared chromatin was incubated with $5 \mu \mathrm{g}$ anti-GABP $\alpha$ (sc-22810X, Santa Cruz). Immune complexes were washed and eluted. Precipitated 
DNA ChIP DNA and input DNA were incubated at $65^{\circ} \mathrm{C}$ to reverse the crosslinking. After digestion with RNase and proteinase $\mathrm{K}$, the ChIP and input DNA were purified with phenol/chloroform extraction and ethanol precipitation. The purified DNA was repaired, ligated with adapter, and amplified by PCR for 15-20 cycles. The amplified DNA was size selected by gel extraction and used for sequencing. Sequencing (36-bp single-end) was performed at the Genomics Core of Memorial Sloan Kettering Cancer Center using HiSeq (Illumina). Reads were first processed with trimmomatic to remove the adapter sequences and bases with quality scores below 20, and reads with less than 30 remaining bases were discarded $^{48}$. Trimmed reads were then aligned to $\mathrm{mm} 10$ mouse genome with the bowtie aligner ${ }^{49}$. GABP peaks were called using MACS2 using $q$ value cutoff $0.01^{50}$. The distribution of the peaks around the TSS was calculated using the ChIPpeakAnno package ${ }^{51}$. DNA motif analysis was performed with the Hypergeometric Optimization of Motif Enrichment program (HOMER) ${ }^{52}$.

ChIP-qPCR. CD4 $4^{+} \mathrm{T}$ cells and of $\mathrm{CD} 8^{+} \mathrm{T}$ cells from WT mice were purified and processed as described in ChIP-seq. The prepared chromatin was incubated with 5 $\mu \mathrm{g}$ anti-GABP $\alpha$ (sc-22810X, Santa Cruz) or control rabbit immunoglobulin (2729, Cell Signaling) overnight. Precipitated DNA from the GABP $\alpha$ antibody and IgG control groups was analyzed by PCR with the following primers:

Mcm 3: 5'-CAGAGAGGACGCTCAAAACC- ${ }^{\prime}$ and 5'-AGAAAAACAGGGGG TGAGGT-3';

Mcm5: 5'-CAAAATGGAGACCGGAAAGA-3' and 5'-GCGGATAGCTATTG GACTGC-3';

Hprt1: 5'-TGAGCGCAAGTTGAATCTG-3' and 5'-GGACGCAGCAACTGAC ATT-3'.

Gene ontology analysis. The BiNGO 3.0.3 plugin for cytoscape was used to determine which gene ontology categories were statistically enriched for the $\mathrm{GABP} \alpha$-regulated genes or GABP $\alpha$ direct target genes identified from the microarray and ChIP-seq experiments ${ }^{53}$.

Immunoblotting. $\mathrm{CD} 4^{+}$and $\mathrm{CD} 8^{+} \mathrm{T}$ cells were purified from spleen and lymph nodes of $\mathrm{CD} 4^{\mathrm{Cre}} \mathrm{Gabpa} a^{\text {f/f }}$ mice and littermate controls by FACS sorting (BD, Aria). In the time course culture experiment, naive T cells were purified, subject to $\alpha$ CD3/28 and IL-2 culture, and collected at indicated time points. Total protein extracts were dissolved in SDS sample buffer, separated on 12\% SDS-PAGE gels and transferred to polyvinylidene difluoride membrane (Millipore). The membranes were probed with antibodies against GABP $($ sc-22810, Santa Cruz), CDK6 (3136, Cell Signaling), Cyclin D2 (3741, Cell Signaling), Mcm3 (4003, Cell Signaling), Mcm5 (A300-195A, Bethyl Laboratories), GADPH (ab9485, Abcam), and $\beta$-actin (AC-15, Sigma), and visualized with the Immobilon Western Chemiluminescent HRP Substrate (Millipore).

Statistical analysis. All data are presented as the mean values \pm SEM. Comparisons between groups were analyzed using unpaired Student's $t$-tests. ns $=$ not significant, ${ }^{*} P<0.05,{ }^{* *} P<0.01,{ }^{* *} P<0.001,{ }^{* * * *} P<0.0001$.

Data availability. Microarray and ChIP-seq data that support the findings of this study have been deposited in GEO with the primary accession code GSE101937.

Received: 21 July 2016 Accepted: 11 August 2017

Published online: 20 October 2017

\section{References}

1. Takada, K. \& Jameson, S. C. Naive T cell homeostasis: from awareness of space to a sense of place. Nat. Rev. Immunol. 9, 823-832 (2009).

2. Surh, C. D. \& Sprent, J. Homeostasis of naive and memory T cells. Immunity. 29, 848-862 (2008).

3. Wang, R. et al. The transcription factor Myc controls metabolic reprogramming upon T lymphocyte activation. Immunity 35, 871-882 (2011).

4. Fischer, A. et al. Severe combined immunodeficiency. A model disease for molecular immunology and therapy. Immunol. Rev. 203, 98-109 (2005).

5. Ouyang, W. \& Li, M. O. Foxo: in command of T lymphocyte homeostasis and tolerance. Trends Immunol. 32, 26-33 (2011).

6. Sharrocks, A. D. The ETS-domain transcription factor family. Nat. Rev. Mol. Cell Biol. 2, 827-837 (2001).

7. Bories, J. C. et al. Increased T-cell apoptosis and terminal B-cell differentiation induced by inactivation of the Ets-1 proto-oncogene. Nature 377, 635-638 (1995).

8. Muthusamy, N., Barton, K. \& Leiden, J. M. Defective activation and survival of T cells lacking the Ets-1 transcription factor. Nature 377, 639-642 (1995).
9. Yamada, T., Park, C. S., Mamonkin, M. \& Lacorazza, H. D. Transcription factor ELF4 controls the proliferation and homing of CD8+T cells via the Kruppel-like factors KLF4 and KLF2. Nat. Immunol. 10, 618-626 (2009).

10. Rosmarin, A. G., Resendes, K. K., Yang, Z., McMillan, J. N. \& Fleming, S. L. GA-binding protein transcription factor: a review of GABP as an integrator of intracellular signaling and protein-protein interactions. Blood Cells Mol. Dis. 32, 143-154 (2004).

11. LaMarco, K., Thompson, C. C., Byers, B. P., Walton, E. M. \& McKnight, S. L. Identification of Ets- and notch-related subunits in GA binding protein. Science 253, 789-792 (1991).

12. Batchelor, A. H., Piper, D. E., de la Brousse, F. C., McKnight, S. L. \& Wolberger, C. The structure of GABPalpha/beta: an ETS domain- ankyrin repeat heterodimer bound to DNA. Science 279, 1037-1041 (1998).

13. de la Brousse, F. C., Birkenmeier, E. H., King, D. S., Rowe, L. B. \& McKnight, S. L. Molecular and genetic characterization of GABP beta. Genes Dev. 8, 1853-1865 (1994).

14. Sawada, J., Goto, M., Sawa, C., Watanabe, H. \& Handa, H. Transcriptional activation through the tetrameric complex formation of E4TF1 subunits. EMBO J. 13, 1396-1402 (1994).

15. Yang, Z. F., Drumea, K., Mott, S., Wang, J. \& Rosmarin, A. G. GABP transcription factor (nuclear respiratory factor 2 ) is required for mitochondrial biogenesis. Mol. Cell. Biol. 34, 3194-3201 (2014).

16. Yang, Z. F., Mott, S. \& Rosmarin, A. G. The Ets transcription factor GABP is required for cell-cycle progression. Nat. Cell. Biol. 9, 339-346 (2007).

17. Ristevski, S. et al. The ETS transcription factor GABPalpha is essential for early embryogenesis. Mol. Cell Biol. 24, 5844-5849 (2004).

18. Xue, H. H. et al. GA binding protein regulates interleukin 7 receptor alphachain gene expression in T cells. Nat. Immunol. 5, 1036-1044 (2004).

19. Briguet, A. \& Ruegg, M. A. The Ets transcription factor GABP is required for postsynaptic differentiation in vivo. J. Neurosci. 20, 5989-5996 (2000).

20. Bottinger, E. P., Shelley, C. S., Farokhzad, O. C. \& Arnaout, M. A. The human beta 2 integrin CD18 promoter consists of two inverted Ets cis elements. Mol. Cell. Biol. 14, 2604-2615 (1994).

21. Yu, S., Jing, X., Colgan, J. D., Zhao, D. M. \& Xue, H. H. Targeting tetramerforming GABPbeta isoforms impairs self-renewal of hematopoietic and leukemic stem cells. Cell Stem Cell 11, 207-219 (2012).

22. Yang, Z. F. et al. GABP transcription factor is required for development of chronic myelogenous leukemia via its control of PRKD2. Proc. Natl Acad. Sci. USA 110, 2312-2317 (2013).

23. Wu, H. et al. The Ets transcription factor GABP is a component of the hippo pathway essential for growth and antioxidant defense. Cell Rep. 3, 1663-1677 (2013).

24. Brenner, D., Blaser, H. \& Mak, T. W. Regulation of tumour necrosis factor signalling: live or let die. Nat. Rev. Immunol. 15, 362-374 (2015).

25. Yu, S., Zhao, D. M., Jothi, R. \& Xue, H. H. Critical requirement of GABPalpha for normal T cell development. J. Biol. Chem. 285, 10179-10188 (2010).

26. Jaworski, A., Smith, C. L. \& Burden, S. J. GA-binding protein is dispensable for neuromuscular synapse formation and synapse-specific gene expression. Mol. Cell. Biol. 27, 5040-5046 (2007).

27. Kerdiles, Y. M. et al. Foxol links homing and survival of naive $\mathrm{T}$ cells by regulating L-selectin, CCR7 and interleukin 7 receptor. Nat. Immunol. 10, 176-184 (2009).

28. Ouyang, W., Beckett, O., Flavell, R. A. \& Li, M. O. An essential role of the Forkhead-box transcription factor Foxol in control of $\mathrm{T}$ cell homeostasis and tolerance. Immunity 30, 358-371 (2009).

29. Yu, S. et al. GABP controls a critical transcription regulatory module that is essential for maintenance and differentiation of hematopoietic stem/progenitor cells. Blood 117, 2166-2178 (2011).

30. Bell, S. D. \& Botchan, M. R. The minichromosome maintenance replicative helicase. Cold Spring Harb. Perspect. Biol. 5, a012807 (2013).

31. Rowell, E. A. \& Wells, A. D. The role of cyclin-dependent kinases in T-cell development, proliferation, and function. Crit. Rev. Immunol. 26, 189-212 (2006).

32. Bertoli, C., Skotheim, J. M. \& de Bruin, R. A. Control of cell cycle transcription during G1 and S phases. Nat. Rev. Mol. Cell Biol. 14, 518-528 (2013).

33. Pamer, E. G. Immune responses to Listeria monocytogenes. Nat. Rev. Immunol. 4, 812-823 (2004).

34. Boros, J. et al. Elucidation of the ELK1 target gene network reveals a role in the coordinate regulation of core components of the gene regulation machinery. Genome Res. 19, 1963-1973 (2009).

35. Hollenhorst, P. C., Shah, A. A., Hopkins, C. \& Graves, B. J. Genome-wide analyses reveal properties of redundant and specific promoter occupancy within the ETS gene family. Genes Dev. 21, 1882-1894 (2007).

36. Okada, Y. et al. Multiple ETS family proteins regulate PF4 gene expression by binding to the same ETS binding site. PLoS ONE 6, e24837 (2011).

37. Park, J. H. et al. Suppression of IL7Ralpha transcription by IL-7 and other prosurvival cytokines: a novel mechanism for maximizing IL-7-dependent $\mathrm{T}$ cell survival. Immunity 21, 289-302 (2004). 
38. Kearsey, S. E. \& Labib, K. MCM proteins: evolution, properties, and role in DNA replication. Biochim. Biophys. Acta 1398, 113-136 (1998).

39. Orr, S. J. et al. Reducing MCM levels in human primary $\mathrm{T}$ cells during the $\mathrm{G}$ (0)-->G(1) transition causes genomic instability during the first cell cycle. Oncogene 29, 3803-3814 (2010).

40. Tsuruga, H. et al. HsMCM6: a new member of the human MCM/P1 family encodes a protein homologous to fission yeast Mis5. Genes Cells 2, 381-399 (1997).

41. Leone, G. et al. E2F3 activity is regulated during the cell cycle and is required for the induction of S phase. Genes Dev. 12, 2120-2130 (1998).

42. Ohtani, K., Tsujimoto, A., Ikeda, M. \& Nakamura, M. Regulation of cell growth-dependent expression of mammalian CDC6 gene by the cell cycle transcription factor E2F. Oncogene 17, 1777-1785 (1998).

43. Crook, M. F. et al. GA-binding protein regulates KIS gene expression, cell migration, and cell cycle progression. FASEB J. 22, 225-235 (2008).

44. Virbasius, J. V., Virbasius, C. A. \& Scarpulla, R. C. Identity of GABP with NRF-2, a multisubunit activator of cytochrome oxidase expression, reveals a cellular role for an ETS domain activator of viral promoters. Genes Dev. 7, 380-392 (1993).

45. Kim, M. V., Ouyang, W., Liao, W., Zhang, M. Q. \& Li, M. O. The transcription factor Foxol controls central-memory CD8+ T cell responses to infection. Immunity 39, 286-297 (2013).

46. Maekawa, Y. et al. Notch2 integrates signaling by the transcription factors RBP-J and CREB1 to promote T cell cytotoxicity. Nat. Immunol. 9, 1140-1147 (2008).

47. Smyth, G. K. Linear models and empirical bayes methods for assessing differential expression in microarray experiments. Stat. Appl. Genet. Mol. Biol. 3, Article3 (2004)

48. Bolger, A. M., Lohse, M. \& Usadel, B. Trimmomatic: a flexible trimmer for Illumina sequence data. Bioinformatics 30, 2114-2120 (2014).

49. Langmead, B., Trapnell, C., Pop, M. \& Salzberg, S. L. Ultrafast and memoryefficient alignment of short DNA sequences to the human genome. Genome Biol. 10, R25 (2009).

50. Zhang, Y. et al. Model-based analysis of ChIP-Seq (MACS). Genome Biol. 9, R137 (2008).

51. Zhu, L. J. et al. ChIPpeakAnno: a bioconductor package to annotate ChIP-seq and ChIP-chip data. BMC Bioinformatics 11, 237 (2010).

52. Heinz, S. et al. Simple combinations of lineage-determining transcription factors prime cis-regulatory elements required for macrophage and B cell identities. Mol. Cell 38, 576-589 (2010).

53. Maere, S., Heymans, K. \& Kuiper, M. BiNGO: a cytoscape plugin to assess overrepresentation of gene ontology categories in biological networks. Bioinformatics 21, 3448-3449 (2005).

\section{Acknowledgements}

We thank members of the Li lab for helpful discussions and critical reading of the manuscript. This work was supported by the National Institutes of Health (RO1 AI102888-01A1 to M.O.L.), a Faculty Scholar Award from the Howard Hughes Medical Institute (M.O.L.), and the Memorial Sloan Kettering Cancer Center Support Grant/Core Grant (P30 CA008748).

\section{Author contributions}

C.T.L. and M.O.L. were involved in all aspects of this study including planning and performing experiments, analyzing and interpreting data, and writing the manuscript. M.H.D., M.R.B., A.T., D.K. and Y.X. assisted with experiments. H.U.O. processed and analyzed microarray and ChIP-seq data, and wrote the manuscript. M.O.L. and C.S.L. oversaw the work performed.

\section{Additional information}

Supplementary Information accompanies this paper at doi:10.1038/s41467-017-01020-6

Competing interests: The authors declare no competing financial interests.

Reprints and permission information is available online at http://npg.nature.com/ reprintsandpermissions/

Publisher's note: Springer Nature remains neutral with regard to jurisdictional claims in published maps and institutional affiliations.

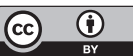

Open Access This article is licensed under a Creative Commons Attribution 4.0 International License, which permits use, sharing, adaptation, distribution and reproduction in any medium or format, as long as you give appropriate credit to the original author(s) and the source, provide a link to the Creative Commons license, and indicate if changes were made. The images or other third party material in this article are included in the article's Creative Commons license, unles indicated otherwise in a credit line to the material. If material is not included in the article's Creative Commons license and your intended use is not permitted by statutory regulation or exceeds the permitted use, you will need to obtain permission directly from the copyright holder. To view a copy of this license, visit http://creativecommons.org/ licenses/by/4.0/

(c) The Author(s) 2017 